\title{
THE IMPORTANCE OF ANALYSIS METHOD FOR BREEDING BIRD SURVEY POPULATION TREND ESTIMATES
}

\author{
LEN THOMAS \\ Centre for Applied Conservation Biology, Faculty of Forestry, University of British \\ Columbia, \#270-2357 Main Mall, Vancouver, British Columbia, V6T 1Z4, Canada. \\ KATHY MARTIN \\ Canadian Wildlife Service, Pacific Wildlife Research Centre, 5421 Robertson Rd, RR1, \\ Delta, British Columbia, V4K 3N2, Canada. \\ and \\ Centre for Applied Conservation Biology, Faculty of Forestry, University of British \\ Columbia, \#270-2357 Main Mall, Vancouver, British Columbia, V6T 1Z4, Canada.
}

Status: $\quad$ Published 1996 in Conservation Biology 10: 479-490

Running Head: $\quad$ BBS ANALYSIS METHODS 


\section{ABSTRACT}

Population trends from the Breeding Bird Survey are widely used to focus conservation effort toward species thought to be in decline, and to test preliminary hypotheses regarding the causes of these declines. A number of statistical methods have been used to estimate population trends, but there is no consensus as to which is the most reliable. In this paper we quantified differences in trend estimates when different analysis methods were applied to the same subset of Breeding Bird Survey data. We estimated trends for 115 species in British Columbia using three analysis methods: U.S. National Biological Service route regression, Canadian Wildlife Service route regression, and nonparametric rank trends analysis. Overall, the number of species estimated to be declining was similar among the three methods, but the number of statistically significant declines was not similar (15, 8 and 29 respectively). In addition, there were many differences among methods in the trend estimates assigned to individual species. Comparing the two route regression methods, Canadian Wildlife Service estimates had a greater absolute magnitude on average than those of the U.S. National Biological Service method. U.S. National Biological Service estimates were on average more positive than Canadian Wildlife Service estimates when the respective agencies data selection criteria were applied separately. These results imply that our ability to detect population declines, and to prioritize species of conservation concern are strongly dependent upon the analysis method used. This highlights the need for further research to determine how best to extract accurate trends from the data. We suggest a method for evaluating the performance of the analysis methods by using simulated Breeding Bird Survey data. 


\section{INTRODUCTION}

There is widespread concern that many North American landbird populations are undergoing long-term declines (Terborgh 1989, 1992; Askins et al. 1990; Askins 1993; Finch \& Stangel 1993). Population monitoring plays three important roles in the conservation of these species: 1) early identification of declining populations focuses research and management effort toward vulnerable species and habitats before they become critically endangered (Hagan 1992), 2) correlations with environmental factors allow the evaluation of preliminary hypotheses of causation (James and McCulloch in press), and 3) ongoing surveillance enables assessment of the effectiveness of management actions (Hellawell 1991). However, monitoring landbird populations is difficult, due to the extensive ranges of most species and the wide variation in population trends among different locations, habitats and time periods (James et al. 1992; Sauer \& Droege 1992; Peterjohn et al. in press). The determination of large-scale changes in population size thus requires accurate trend information over a long time period and a large geographic area.

For North American landbirds, the primary source of population information at these scales is the North American Breeding Bird Survey (BBS), a volunteer-based population monitoring program administered cooperatively by the U.S. National Biological Service (USNBS) and the Canadian Wildlife Service (CWS). While there are a number of limitations inherent in the survey methodology (Robbins et al. 1986; Droege 1990; Peterjohn et al. in press), the BBS is the only systematic surveillance program that covers the breeding ranges of most landbird species. Summaries containing species trends have been published regularly by the USNBS and CWS (e.g., Erskine et al. 1992; Peterjohn and Sauer 1993), as have more detailed accounts for some species (e.g., Sauer and Droege 1990a, 1990b) and analyses of multispecies patterns (e.g., Robbins et al. 1989; Sauer and Droege 1992). Trends from the BBS have been used by third parties for conservation prioritization schemes (Carter \& Barker 1993; Hunter et al. 1993a, 1993b; 
Smith et al. 1993; Thompson et al. 1993), for population status reviews (e.g., Terborgh 1989; Askins et al. 1990; Askins 1993), for tests of hypotheses of causation (e.g., Böhning-Gaese et al. 1993; Johnson and Schwartz 1993) and as a benchmark in the validation of other surveillance programs (Holmes \& Sherry 1988; Hagan et al. 1992; Hussell et al. 1992; Witham \& Hunter 1992). Thus: "Population trend determinations by the BBS have become the accepted measure of North American breeding bird populations.” (Morton 1992: 585.)

Although BBS data have been collected in a standardized manner since the survey began, methods of data analysis have been evolving continually. The estimation of population trends using extensive count data such as that produced by the BBS is a considerable statistical challenge: analysis methods must take account of complications inherent in the survey such as missing data, intra- and inter- observer variation and the non-linearity of long-term trends over space and time (see review in Thomas in press). Early analyses by the USNBS and CWS used a method developed for use with the British Common Bird Census (“base-year index”, Taylor 1965). However, this method was shown to be unreliable (Geissler and Noon 1981), and more recent analyses have been based on the "route regression" approach developed by Giessler (1984). In addition, a number of independent researchers have suggested and implemented alternative approaches (Titus 1990; Moses and Rabinowitz 1990; James et al. 1992; Böhning-Gaese et al. 1993; James et al. in press). These methods differ in the way they deal with the difficulties outlined above; however, despite some discussion in the literature (Geissler and Noon 1981; James et al. 1990; Titus 1990; Peterjohn et al. in press; van Strien et al. in press), there is no consensus as to which is the most suitable (see Thomas in press). In this paper, we focus on the practical consequences of the different analysis methods for those that use BBS trend information. We compare trend estimates produced by different analysis methods applied to the same data, and discuss the implications of any observed differences in estimates for our ability to detect population 
declines and to prioritize species of conservation concern. We use three analysis methods: USNBS route regression (Geissler and Sauer 1990), CWS route regression (Erskine et al. 1992) and rank-trends analysis (Titus 1990) on a common set of BBS data from British Columbia. The first two methods were used by the two agencies in their most recent published reports. They are based on a similar approach (route regression), but differ in the way that this approach is implemented. The third method is a nonparametric technique that estimates the direction of trend (i.e., whether the population is increasing or decreasing), but not its magnitude.

\section{METHODS}

\section{BREEDING BIRD SURVEY}

The Breeding Bird Survey comprises approximately 3000 39.2km long survey routes selected at random along secondary roads within all states/provinces in North America. Each year, during late May or June, a volunteer observer drives the survey route, stopping every $0.8 \mathrm{~km}$ and recording all the birds seen or heard within a 400 meter radius in a three minute period (Robbins et al. 1986: Appendix B). Approximately 70\% of routes are surveyed each year.

Here, we used all routes in British Columbia that were surveyed between 1968 and 1992, excluding those from physiographic strata 29, 30 and 68 (Closed Boreal Forest, Aspen Parklands and Northern Rocky Mountains respectively, Butcher 1990), since they are rarely surveyed, and are not normally included in quantitative analyses of BBS data (J. R. Sauer, USNBS Patuxent Environmental Science Center, personal communication). Our data set thus included 87 routes (856 individual surveys) within physiographic strata 63, 64 and 94 (Fraser Plateau, Central Rocky Mountains and Northern Pacific Rainforests).

\section{DATA SELECTION}


Population trend analysis from BBS data involves two stages: data selection and trend estimation. Data selection criteria are designed to screen out surveys performed under questionable conditions, and to ensure that there are sufficient data to meet the requirements of the trend estimation procedure. Criteria depend largely upon the judgement of the analyst and vary widely among published analyses (Thomas in press). The selection procedures used by the USNBS and CWS are similar, but differ in the criteria for the exclusion of individual surveys and the minimum data requirements of the route regression procedures. Standard data selection protocols for rank-trends analysis have not been developed. Since we were chiefly interested in differences due to trend estimation method we based our comparisons of the three methods on the common subset of data that passed both current USNBS and CWS criteria, as provided by J. R. Sauer (USNBS, personal communication) and B. T. Collins (CWS National Wildlife Research Centre, personal communication). Nevertheless, in order to determine the effect of data selection, we also compared the results from the two route regression methods produced using their respective agency’s data selection protocols.

USNBS criteria: 1) Only surveys performed within a regionally specified range of dates, times and weather conditions, and by qualified observers were included in the analysis (i.e., surveys with USNBS survey codes one, two or three). 2) Routes with too few surveys remaining to enable estimation of trend and trend variance were then excluded (i.e., where number of surveys minus number of observers was less than two). 3) Routes on which no birds of the species under analysis had been seen were also discarded. 4) If (after data selection) the species had fewer than 10 routes remaining or had a mean count of less than 1.0 birds per survey, trend estimates were not calculated for that species.

CWS criteria: 1) Surveys that did not meet CWS survey criteria were discarded. These criteria are similar (but not identical) to those used in USNBS criterion 1. 2) Routes with too few surveys remaining to enable estimation of trend (but not trend 
variance) were then excluded (i.e., where the number of surveys minus number of subroutes was less than one. A subroute is a subset of the surveys done on a single route such that all surveys in a subroute were performed by the same observer within a span of 19 or fewer calendar days across years and under similar weather conditions. Subroute designations were provided by B.T. Collins). Criteria 3 and 4 were identical to those used by the USNBS.

\section{TREND ESTIMATION}

The three trend estimation methods are summarized in Table 1 and are described in detail below.

USNBS route regression: In route regression, the overall trend for the region and species of interest is calculated using the weighted average of the trend on each route (see below). A route trend is the slope of a log-linear regression of birds counted (dependent variable) against time (independent variable). We performed the analysis described here using programs written in C++, following the methods of Geissler (1984), Geissler \& Sauer (1990) and Peterjohn et al. (in press), with additional details provided by J. R. Sauer (personal communications). Our programs included some numerical routines written by Press et al. (1992).

For each route, we computed the natural logarithm of the number of birds counted (plus 0.5 to accommodate zero counts; Component 1, Table 1). Route trends were calculated on the logarithmic scale as the slope of the regression of log count on year of count (Component 2). To account for differences among observers we treated them as covariables in the regression (Component 3). We then back-transformed the route trends using the method developed by Bradu \& Mundlac (1970), which is approximately equal to taking the exponent of the trend estimate minus one-half of its variance (Component 4). 
The overall species trend for British Columbia was calculated using the weighted mean of the back-transformed route trends (Component 5), in two stages as follows. We first calculated the weighted mean slope for each physiographic area, weighting backtransformed route trends by the marginal mean count on the route (Searle et al. 1980; Component 6), and a measure of the reliability of the route trend estimate, calculated as the variance of the slope divided by the mean square error for the route-specific regression (Component 7). The marginal mean is an estimate of the count that would have been recorded in the mid-year of the analysis period (i.e., 1980) by an average observer. Geometric mean count was used in place of marginal mean on routes where estimating the marginal mean required extrapolating beyond the years when counts took place. In this context geometric mean was defined as the arithmetic mean of the logtransformed counts, backtransformed onto the multiplicative scale. We then calculated the overall trend as the mean of the trends for each physiographic stratum, weighted by the stratum area (Component 8).

We estimated the variance of the overall trend estimate from 400 bootstrapped subsamples of the routes within physiographic strata (Component 10). Bootstrapping is a technique that allows the estimation of the sampling distribution of a non-standard statistic (in this case the overall trend estimate). Many repeat subsamples are taken with replacement from the original data and the distribution of the statistic in the subsamples is taken as the best indication of the true distribution of the statistic (Efron 1982). We also used the mean of the bootstrapped trend estimates as the final species trend since it is in theory less biased than the original estimate. Statistical significance of the trend was assessed using a z-test (Component 11). This tested the alternate hypothesis that routes show consistent log-linear trends with a slope different from zero across physiographic strata within the study area.

CWS route regression: The CWS method also uses route regression to calculate regional trends from a weighted average of the trend on each route. However it differs 
from the USNBS method in the way the route trends are calculated, the method of averaging route trends and the weightings used to produce the regional trend. We performed this analysis using a FORTRAN program supplied by B. T. Collins, which implements the methodology of Erskine et al. (1992; see also Collins and Wendt 1989).

As with the USNBS route regression, we calculated route trends as the slope of the regression of the natural logarithm of counts on year of count (Components 1, 2 and 3). In this case 0.23 (rather than 0.5 ) was added to each count before log transforming to accommodate zero counts, and subroutes were used as covariables in the regression (rather than observers; see CWS data selection criteria for a definition of subroutes).

We calculated the species trend for British Columbia directly from the weighted mean of the route trends, still on the logarithmic scale (Component 5). The weightings used were the marginal mean count on the route (Searle et al. 1980; Component 6), a precision estimate given by the squared deviations of the counts from the subroute mean (Component 7), and an area weighting (Component 8). We constrained the marginal mean so that it could not exceed the maximum number of birds seen on all routes, or 200, whichever was the least. The area weightings were provided by B.T. Collins and these consider the number of routes and the proportion of land area in each degree-block.

We then back-transformed the overall trend estimate to the arithmetic scale by simple exponentiation (Component 9), and calculated the variance of the estimate by jackknifing (Component 10). Jackknifing is similar to bootstrapping, except that in this case the population distribution of the statistic (overall trend estimate) is approximated using the set of subsamples generated when one data point (route) is removed from the sample in turn (Efron 1982). Unlike the USNBS method, no bias adjustment was performed. The statistical significance of the alternate hypothesis, that there are consistent non-zero log-linear trends across routes in British Columbia, was calculated using a $t$-test, with the degrees of freedom equal to the number of routes minus one (Component 11). 
Nonparametric rank trend analysis: With this method, trend statistics are calculated separately for each route using a nonparametric ranking procedure, and are summed to produce regional trend statistics. This enables calculation of the direction (increasing or decreasing) and statistical significance of the trend, but not its magnitude (the size of increase or decrease). The procedure described in Titus et al. (1990) was implemented fully with a C++ program, and will be briefly summarized here.

On each route, we arranged counts in ascending order and assigned ranks, giving ties the mean of the tied ranks. We calculated a trend statistic, $D$, for each route as the sum of $\left(R_{i}-i\right)^{2}$, where $R_{i}$ is the rank of the $i$ th yearly count (i.e. $i=1$ in 1968 to 25 in 1992; Component 2). If counts tend to increase over time on the route then $\mathrm{D}$ will be small, and if counts tend to decrease over time then $D$ will be large. Under the null hypothesis of random change in count over time, this statistic is normally distributed with an expected mean and variance that can be easily calculated (Lehman 1975). To test the alternate hypothesis, that counts on routes tend to increase or decrease over time throughout British Columbia, we summed the values of $D$ (Component 5), the expected mean of $D$ and the expected variance of $D$ (Component 10) over routes and performed a z-test (Component 11).

\section{COMPARISON OF TREND ESTIMATES}

For each pairwise combination of methods, we quantified differences in trend estimates by calculating the proportion of species with trends in different directions (i.e., increasing in one method but decreasing in the other). We also calculated the proportion of differences in statistical significance (i.e., $p<=0.05$ in one method but $p>0.05$ in the other). In order to determine whether the differences were related to sample size (number of routes) or species abundance (mean count per survey), we performed logistic regressions on the proportion of differences (dependent variable) against sample size and log species abundance (independent variables). 
For the two route regression methods, we further examined the pattern of differences by plotting estimates of trend against one another and determining the slope of the principal axis (Model II regression, Sokal and Rohlf 1981). If the two methods produce similar trends on average then the principal axis will have a slope of 1.0 and run through the origin. We also calculated the median absolute difference between trends, and determined whether this was related to sample size or log species abundance using linear regression.

\section{RESULTS}

Of the 265 species recorded at least once, 119 passed both USNBS and CWS data selection standards. For this common subset of the data, 4 species had estimated annual rates of population change of greater than 15\% per year using CWS route regression (Tennessee warbler Vermivora peregrina: $+18.8 \%$; Black tern Chlidonias niger: $+22.5 \%$; Magnolia warbler Dendroica magnolia: -33.6\%; Black swift Cypseloides niger: $+41.8 \%$; see Discussion). These extreme trends are biologically implausible, so we excluded them from further analysis. For the remaining 115 species, the median sample size was 39 routes (range 10 - 61) and the median abundance was 4.76 birds per survey (range 1.09 - 62.86).

Using these data, about the same number of species were estimated to be increasing or decreasing in all three methods (Fig. 1). However, there was considerable variation among methods in the species making up these totals: the proportion of species assigned different trends ranged between 0.21 and 0.33 , depending upon the pair of methods being compared (Table 2). The proportion of differences did not appear to be strongly related to sample size or species abundance (Table 3). Our estimates had quite large confidence intervals (Table 3), so we cannot rule out the possibility that we did not have enough samples ( $N=115$ species) to detect such an effect had one occurred. 
However, in many cases, the estimates were in the opposite direction to that predicted (i.e., proportion of differences increased with increasing sample size and abundance).

There were large differences among methods in the overall number of species estimated to be undergoing statistically significant population changes, with USNBS route regression assigning almost twice as many species significant trends as CWS route regression, and nonparametric rank trends assigning twice as many again as the USNBS method (Fig. 1). The proportion of species assigned trends of different significance levels was between 0.18 and 0.43 (Table 2), and again did not appear to be strongly related either to species abundance or sample size (Table 3). Our comments about sample size are relevant here also. In all comparisons (i.e., direction and significance), the two route regression methods were the most similar, while the greatest differences were between CWS route regression and rank-trends analysis (Table 2).

For the two route regression methods, there was little overall difference in trend estimates (median difference USNBS trend - CWS trend $=+0.04 \%$ per year; $95 \%$ confidence limits estimated from 10000 bootstrap subsamples of the 115 species $=-0.60$ and +0.44$)$. However, the absolute magnitudes of trends were greater in CWS route regression trends than in the USNBS method: negative trends tended to be more negative and positive trends tended to be more positive (Fig 2., slope of principal axis $=0.58,95 \%$ parametric confidence limits $=0.45$ and 0.72 ). There was considerable scatter about this overall pattern (Fig. 2.), with the median absolute difference in magnitude of trends being $1.19 \%$ per year, (range 0.00 - 13.06).

Contrary to our results for the proportion of differences in the direction and significance of trends, the mean absolute difference in the magnitude of trends decreased with increasing sample size (slope of linear regression: -0.46; 95\% parametric confidence limits $=-0.87$ and -0.05 ) and with increasing log species abundance (slope: $-0.044 ; 95 \%$ parametric confidence limits $=-0.067$ and -0.020 ), although in both cases the proportion of variance explained by the relationship was small $\left(r^{2}=0.04\right.$ and 0.11 respectively). 
We speculated that this may be due to decreasing variance of the estimates, since variance decreases with increasing sample size, and sample size and log abundance were correlated (Pearson $r=0.44$ ). In order to test this, we corrected for decreasing variance by dividing the difference in trend estimates by the square root of the sum of their variances, to yield $z$-statistics. The absolute magnitude of these $z$-statistics did not appear to vary with sample size or with log abundance in linear regressions (sample size: slope $=-0.002 ; 95 \%$ parametric confidence limits: $-0.008,+0.005 ; r^{2}=0.00 ; \log$ abundance: slope $=0.05 ; 95 \%$ parametric confidence limits: $-0.06,+0.16 ; r^{2}=0.02$ ), indicating that the increasing similarity between trend estimates with sample size and abundance was indeed explained by decreasing variance. We conclude that trend estimates that have low variance when derived using route regression are less sensitive to the particular variant of route regression used.

Finally, wed evaluate the effect of data selection criteria. When only USNBS data criteria were applied to the data, the average species dataset contained 3.5 more routes (median sample size $=42.5$ routes, range $11-64$ ), and the median trend estimated using USNBS route regression was $0.45 \%$ per year higher than when both data selection criteria were applied (range 1.20 lower to 6.02 higher). For CWS data selection criteria alone, the average increase in sample size was 2 (median sample size $=41$ routes, range 10 - 62), and the median trend was $0.07 \%$ per year lower (range 4.36 lower to 2.90 higher). Comparing USNBS route regression and CWS route regression using trend estimates derived from the datasets appropriate to each, these changes caused the USNBS method to produce on average more positive trends than the CWS method (median difference USNBS trend - CWS trend $=+0.73 \%$ per year; $95 \%$ confidence limits estimated from 10000 bootstrap subsamples $=+0.36$ and +1.01 ). This is dissimilar to the result using the uniform data set, where both methods produced similar trends on average. We therefore conclude that data selection criteria can have an important effect on the results obtained. 


\section{DISCUSSION}

The Breeding Bird Survey is the most comprehensive source of data available for monitoring trends in North American landbird populations, and for prioritizing species of conservation concern. We have shown that the method of trend estimation can affect the magnitude, direction and statistical significance of population trends assigned to species. In addition, small changes in the way that data are selected for analysis can affect the overall magnitude of trends. In this section we consider possible causes of the differences, their implications for users of BBS trend information, and suggest some priorities for further work.

\section{CAUSES OF THE DIFFERENCES}

Our study was not designed to explicitly test which of the many differences between the methods caused the observed differences in trend estimates. Nevertheless, based on the predicted effect of differences between the methods (Table 1) and some preliminary analyses, we can suggest which components of the methods could account for our results. In summary, our results were: 1) large differences in the number of statistically significant trends among the three methods; 2) greater absolute magnitude of trends in CWS route regression compared with the USNBS method; 3) slightly more positive trends in the USNBS method compared with CWS route regression when the respective agencies' data selection criteria were applied separately; and 4) large variation about these patterns in the direction, magnitude and significance of trends. We deal with each of these in turn.

Differences in the number of statistically significant trends were consistent with differences in the way that regional trends and trend variances were calculated by the different methods, although many other factors may have been involved. Nonparametric rank trends analysis produced the greatest proportion of statistically significant results, 
probably because it did not consider between-route variance when calculating the expected variance of the regional trend (Component 10, Table 1). USNBS route regression produced more statistically significant results than CWS route regression. The USNBS method tested for consistency of trends nested within physiographic areas, while CWS route regression tested for consistency of trends over the whole region (Component 5). Hence in the USNBS method, the variance of trends among physiographic areas was removed from the statistical test (analogous to a nested analysis of variance), resulting in an increased chance that the trend was significant.

The greater absolute magnitude of trends in CWS route regression relative to the USNBS method may have been due to differences in the constant added before logtransformation (Component 1). Addition of a constant biases the trend towards 0 , and this effect is stronger for larger values of the constant (Geissler and Link 1988; Collins 1990). The constant was larger in the USNBS method than in the CWS method (0.5 vs. 0.23), so the potential bias in USNBS route regression was greater. The bias is also stronger for low abundance species (Geissler and Link 1988; Collins 1990). We thus predicted that if differences in constant were causing the observed differences in absolute magnitude of trend, the effect would be greater for low abundance species than those with high abundance. We tested this possibility by dividing the 115 species into two equal groups by abundance and calculating the slope of the principal axis separately for each group (one species was excluded from the test to make both groups of equal size). The median abundance in the low abundance group was 2.08 birds per survey (range 1.09 - 4.59), and the slope of the principal axis was 0.52 (95\% parametric confidence limits 0.32, 0.76). For the high abundance group, the median abundance was 8.29 birds per survey (range 4.96 - 62.86) and the slope of the principal axis was 0.63 (95\% parametric confidence limits $0.49,0.79$ ). The slopes vary in the anticipated direction (low abundance group smaller) but are clearly not significantly different. Simulations performed by Collins (1990) showed that the bias due to addition of a constant decreases 
rapidly with increasing abundance. We thus suspect that the minimum data requirement for a mean of at least 1.0 birds per survey was effective in controlling the difference in bias to below the level that we could detect statistically. Other explanations must account for most of the observed difference in the absolute magnitude of trends between route regression methods.

The overall difference in USNBS trends resulting from differences in data selection criteria currently defies explanation. We cannot imagine any scenario in which the small differences in data selected would cause systematic differences in trend. Our results highlight the need for standardization of data selection, since many published analyses use data selection criteria even more divergent than the two we compared here (e.g., Böhning-Gaese et al. 1993; James et al. in press).

Differences in trend estimates among methods that are not explained by the above patterns are likely due to the additive effect of the many differences among the methods, each acting independently. Of these, we predict that the most important are the weightings used when combining route trends to produce trends for the region (Components 6, 7 and 8). These weightings are designed to correct for geographic variation in the number of routes and the abundance of birds, and to increase the precision of the regional trend estimate. The method of calculating the weightings differs between route regression methods, which can result in differences of up to three orders of magnitude in the weightings assigned individual routes. No system of weightings has been developed for use with nonparametric rank trends analysis. The importance of weightings is demonstrated by the four species assigned improbably large trend estimates in CWS route regression and excluded from the comparisons. In all four of these species, one route with a large apparent change in the density of birds but few surveys was assigned a very large abundance weighting (due to the extrapolation of the route trend to calculate the least squares mean) and thus dominated the regional trend estimate. The abundance weighting was calculated differently in USNBS route 
regression (geometric mean was used where extrapolation was necessary), and these routes were assigned small weightings, leading to more credible regional trend estimates for the four species.

\section{IMPLICATIONS OF THE RESULTS}

In order to be effective, conservation programs must be based upon accurate information. Partners in Flight, the multi-agency coalition responsible for initiating the Neotropical Migratory Bird Conservation Program (Hagan 1992; Finch and Stangel 1993), has defined an effective monitoring scheme as one that has a $90 \%$ chance of detecting a 50\% decline in species abundance over 25 years (Butcher et al. 1993). We have shown here that for British Columbia BBS data the direction, magnitude and significance of trends attributed to species shows considerable variation due to analysis method alone. For the two route regression methods, which used a similar approach, 15 of 115 species (17\%) showed a difference in the magnitude of the trend due to analysis method of greater than $50 \%$ over the 25 years analyzed. For these species the uncertainty due to analysis method alone was larger than the absolute change in population size that Partners in Flight wishes to detect. Differences in the magnitude of route regression estimates were related to sample size (number of routes in the analysis); hence, we expect these differences to be smaller for estimates based on larger geographic areas or states/provinces with a greater density of routes (e.g., those in eastern North America). We do not know whether trend estimates from methods based on very different assumptions, such as nonlinear nonparametric route regression (James et al. 1992) or Mountford’s method (Mountford 1982), will show similar convergence with increasing sample size.

A number of species prioritization schemes have used the statistical significance of the trend estimate as one criterion for setting the conservation priority of a species (Thompson et al. 1993; Hunter et al. 1993b; Smith et al. 1993). Our results show large 
differences among methods in the statistical significance assigned to species (Table 2), with no consistent increase in similarity with increasing sample size or abundance (Table 3). Of the 31 species estimated to be showing significant declines (i.e., $p<0.05$ ) by one or more of the methods, 15 (47\%) were estimated to be declining significantly by USNBS route regression, 8 (25\%) by CWS route regression and 29 (91\%) by rank-trends analysis. Hence species prioritization schemes based upon the statistical significance of trends are likely to highlight a very different set of species depending upon which analysis method is used.

The differences reported here indicate that analysis method will also affect the results of geographic analyses of the significance of population trends (e.g., Sauer and Droege 1990a, b; Peterjohn and Sauer in press). We do not know whether analysis method will influence the outcome of multispecies comparisons (e.g., Böhning-Gaese et al. 1993; Peterjohn and Sauer 1993; James et al. in press), since differences in individual species trends may “average out” when species are grouped (Fig 1). We thus tentatively support Droege (1990:3) in his statement: "Statistical analyses of these data and their subsequent interpretation should dwell on the patterns of population change rather than on the magnitudes of calculated trends and variances.”

Readers without expertise in the statistics of trend analysis should not be dismayed by our results. As we pointed out in the introduction, the analysis of count data is recognized as problematic among statisticians, and current estimation methods are continually being improved. Wise users of trend information should always bear in mind the limitations of the program, and seek to corroborate the results with those from independent sources. Nevertheless, the BBS remains our most valuable source of North American trend data for bird populations, and judiciously interpreted results should continue to play a role in conservation decisions. We hope that our findings stimulate further research to compare analysis methods that will ultimately increase our confidence in BBS trend estimates. 


\section{PRIORITIES FOR FURTHER WORK}

In this paper, we have demonstrated that the manner in which BBS data are selected and analyzed can affect the result obtained and inferences drawn. Our results raise two important questions: 1) which components of the methods have the largest effect on the resulting estimates, and 2) which method is the most accurate? The first question requires a detailed comparison of many variants of each method applied to the same dataset. This type of study would act as a sensitivity analysis, enabling detailed methodological research (e.g., Sauer et al. 1994) to focus on the aspects of the methods that are the most sensitive to the approach used. The second question is much harder to resolve. Comparisons of results among methods cannot determine which method is the most accurate, as there is no benchmark with which to compare the estimates. True population trends in British Columbia, or for any other large geographic part of the continent, are unknown for any species monitored. One possibility is to compare results to those from other surveillance programs, such as migration monitoring from bird observatories or checklist programs (e.g., Hussel et al. 1992). However, this approach is flawed: since all programs measure trends with error, neither concordance nor lack of it can be used to infer which method is biased.

We thus suggest the use of simulated BBS data, where "known trends" are generated a priori, to compare analysis methods. Trends should be simulated under a variety of realistic scenarios, such as those suggested by Wilcove \& Terborgh (1984). In general, the most appropriate method will be the one that gives the most accurate results over the widest range of conditions. An example of the approach is given in Thomas (in press) and we are currently preparing a more extensive set of simulated data. We hope evaluate methods outlined here, plus a number of other analytical approaches including Mountford's method (Mountford 1982), the impution of missing values (Moses and Rabinowitz 1990), estimating equations (Link and Sauer 1994), nonlinear nonparametric 
and semiparametric route regression (James et al. in press), and Poisson regression (van Strien et al. in press).

The BBS has the potential to provide population trends for the majority of breeding birds in North America over a large part of their ranges. Although trend estimation from BBS data is a formidable statistical challenge, many of the causes of bias are predictable and can be minimized by the choice of a method appropriate to the hypothesis under examination. Given the current high levels of concern about population trends of North American landbirds it is clearly imperative that we determine how best to draw inference from the wealth of information that is collected by the BBS each year.

\section{ACKNOWLEDGMENTS}

We are grateful to the thousands of volunteers who have collected BBS data through the years. We thank B. T. Collins for providing the CWS route regression program, and B. G. Peterjohn and J. R. Sauer for help with the details of the USNBS route regression method. Reviews by B. T. Collins, C. Downes, E. H. Dunn, J. M. Hagan, B. G. Peterjohn and J. R. Sauer helped to improve previous versions of this manuscript. This research was supported by the Natural Sciences and Engineering Research Council of Canada, the National Wildlife Research Centre (CWS, Ottawa), the CWS, Pacific and Yukon Region, and through a Canadian Commonwealth Scholarship to LJT.

\section{LITERATURE CITED}

Askins, R. A. 1993. Population trends in grassland, shrubland, and forest birds in eastern North America. Current Ornithology 11:1-34. 
Askins, R. A., J. F. Lynch, and R. S. Greenberg. 1990. Population declines in migratory birds in eastern North America. Pages 1-57 in R. F. Johnston, editor. Current Ornithology. . Volume 7. Plenum Press, New York.

Böhning-Gaese, K., M. L. Taper, and J. H. Brown. 1993. Are declines in North American insectivorous songbirds due to causes on the breeding range? Conservation Biology 7:76-86.

Bradu, D., and Y. Mundlac. 1970. Estimation in lognormal linear models. Journal of the American Statistical Association 65:198-211.

Butcher, G. S. 1990. Audubon Christmas Bird Counts. Pages 5-14 in J. R. Sauer and S. Droege, editors. Survey Designs and Statistical Methods for the Estimation of Avian Population Trends. Biological Report 90(1). U.S. Fish and Wildlife Service, Washington D.C.

Carter, M. F., and K. Barker. 1993. An interactive database for setting conservation priorities for western Neotropical migrants. Pages 120-144 in D. M. Finch and P. W. Stangel, editors. Status and Management of Neotropical Migratory Birds; Proceedings of the 1992 Partners in Flight National Training Workshop; September 21-25; Estes Park, Colorado. General Technical Report RM-229. U.S.D.A. For. Serv. Rocky Mountain Forest and Range Experiment Station, Fort Collins, Colorado.

Collins, B. T. 1990. Using rerandomization tests in route-regression analysis of avian population trends. Pages 63-70 in J. R. Sauer and S. Droege, editors. Survey Designs and Statistical Methods for the Estimation of Avian Population Trends. Biological Report 90(1). U.S. Fish and Wildlife Service, Washington D.C. 
Collins, B. T., and J. S. Wendt. 1989. The Breeding Bird Survey in Canada, 1966-1983:

Analysis of Trends in Breeding Bird Populations. Technical Report 75. Canadian Wildlife Service, Ottawa, Ontario.

Droege, S. 1990. The North American Breeding Bird Survey. Pages 1-4 in J. R. Sauer and S. Droege, editors. Survey Designs and Statistical Methods for the Estimation of Avian Population Trends. Biological Report 90(1). U.S. Fish and Wildlife Service, Washington D.C.

Efron, B. 1982. The Jackknife, the Bootstrap and Other Resampling Plans. . Society for Industrial and Applied Mathematics, Philadelphia, Pennsylvania.

Erskine, A. J., B. T. Collins, E. Hayakawa, and C. Downes. 1992. The Cooperative Breeding Bird Survey in Canada, 1989-91. Progress Note 199. Canadian Wildlife Service, Ottawa, Ontario.

Finch, D. M., and P. W. Stangel. 1993. Introduction. Pages 1-4 in D. M. Finch and P. W. Stangel, editors. Status and Management of Neotropical Migratory Birds; Proceedings of the 1992 Partners in Flight National Training Workshop; September 2125; Estes Park, Colorado. General Technical Report RM-229. U.S.D.A. For. Serv. Rocky Mountain Forest and Range Experiment Station, Fort Collins, Colorado.

Geissler, P. H. 1984. Estimation of animal population trends and annual indices from a survey of call-counts or other indications. Proceedings of the American Statistical Association, Section on Survey and Research Methods 1984:472-477. 
Geissler, P. H., and B. R. Noon. 1981. Estimates of avian population trends from the North American Breeding Bird Survey. Pages 42-51 in C. J. Ralph and J. M. Scott, editors. Estimating numbers of terrestrial birds. Studies in Avian Biology 6. Cooper Ornithological Society, Lawrence, Kansas.

Geissler, P. H., and J. R. Sauer. 1990. Topics in route-regression analysis. Pages 54-57 in J. R. Sauer and S. Droege, editors. Survey Designs and Statistical Methods for the Estimation of Avian Population Trends. Biological Report 90(1). U.S. Fish and Wildlife Service, Washington D.C.

Hagan, J. M. 1992. Conservation biology when there is no crisis - yet. Conservation Biology 6:475-476.

Hagan, J. M., T. L. Lloyd-Evans, J. L. Atwood, and D. S. Wood. 1992. Long-term changes in migratory landbirds in the north-eastern United States: evidence from migration capture data. Pages 115-130 in J. M. Hagan and D. W. Johnston, editors. Ecology and Conservation of Neotropical Migrant Landbirds. . Smithsonian Institution Press, Washington D.C.

Hellawell, J. M. 1991. Development of a rationale for monitoring. Pages 1-14 in F. B. Goldsmith, editor. Monitoring for Conservation and Ecology. . Chapman and Hall, London, U.K.

Holmes, R. T., and T. W. Sherry. 1988. Assessing population trends of New Hampshire forest birds: Local vs. regional patterns. The Auk 105:756-768. 
Hunter, W. C., M. F. Carter, D. N. Pashley, and K. Barker. 1993a. The Partners in Flight species prioritization scheme. Pages 109-120 in D. M. Finch and P. W. Stangel, editors. Status and Management of Neotropical Migratory Birds; Proceedings of the 1992 Partners in Flight National Training Workshop; September 21-25; Estes Park, Colorado. General Technical Report Rm-229. U.S.D.A. For. Serv. Rocky Mountain Forest and Range Experiment Station, Fort Collins, Colorado.

Hunter, W. C., D. N. Pashley, and R. E. F. Escano. 1993b. Neotropical migratory landbird species and their habitats of special concern within the southeast region. Pages 159-171 in D. M. Finch and P. W. Stangel, editors. Status and Management of Neotropical Migratory Birds; Proceedings of the 1992 Partners in Flight National Training Workshop; September 21-25; Estes Park, Colorado. General Technical Report RM-229. U.S.D.A. For. Serv. Rocky Mountain Forest and Range Experiment Station, Fort Collins, Colorado.

Hussell, D. J. T., M. H. Mather, and P. H. Sinclair. 1992. Trends in numbers of tropicaland temperate-wintering migrant landbirds in migration at Long Point, Ontario, 19611988. Pages 101-114 in J. M. Hagan and D. W. Johnston, editors. Ecology and Conservation of Neotropical Migrant Landbirds. . Smithsonian Institution Press, Washington, D.C.

James, F. C., and C. E. McCulloch. In Press. The strength of inferences about causes of trends in bird populations. in D. M. Finch and T. E. Martin, editors. Ecology and Management of Neotropical Migrant Birds: a Synthesis and Review of the Critical Issues. . Oxford University Press, Oxford, U.K. 
James, F. C., C. E. McCulloch, and L. E. Wolfe. 1990. Methodological issues in the estimation of trends in bird populations with an example: the Pine Warbler. Pages 84-98 in J. R. Sauer and S. Droege, editors. Survey Designs and Statistical Methods for the Estimation of Avian Population Trends. Biological Report 90(1). U.S. Fish and Wildlife Service, Washington D.C.

James, F. C., D. A. Wiedenfeld, and C. E. McCulloch. 1992. Trends in breeding populations of warblers: declines in the southern highlands and increases in the lowlands. Pages 43-56 in J. M. Hagan and D. W. Johnston, editors. Ecology and Conservation of Neotropical Migrant Landbirds. . Smithsonian Institution Press, Washington D.C.

James, F. C., C. E. McCulloch, and D. A. Wiedenfeld. In Press. New approaches to the analysis of population trends in land birds. Ecology.

Johnson, D. H., and M. D. Schwartz. 1993. The Conservation Reserve Program and grassland birds. Conservation Biology 7:934-937.

Lehman, E. L. 1975. Nonparametrics - Statistical Methods Based on Ranks. . HoldenDay Inc., San Francisco, California.

Link, W. A., and J. R. Sauer. 1994. Estimating equation estimates of trends. Bird Populations 2:23-32.

Morton, E. S. 1992. What do we know about the future of migrant landbirds? Pages 7584 in J. M. Hagan and D. W. Johnston, editors. Ecology and Conservation of Neotropical Migrant Landbirds. . Smithsonian Institution Press, Washington D.C. 
Moses, L. E., and D. Rabinowitz. 1990. Estimating (relative) species abundance from route counts of the Breeding Bird Survey. Pages 71-79 in J. R. Sauer and S. Droege, editors. Survey Designs and Statistical Methods for the Estimation of Avian Population Trends. Biological Report 90(1). U.S. Fish and Wildlife Service, Washington D.C.

Mountford, M. D. 1982. Estimation of population fluctuations with application to the Common Bird Census. Applied Statistics 31:135-143.

Peterjohn, B. G., and J. R. Sauer. 1993. North American Breeding Bird Survey annual summary 1990-1991. Bird Populations 1:1-15.

Peterjohn, B. G., J. R. Sauer, and C. S. Robbins. in press. The North American Breeding Bird Survey and population trends of Neotropical migrant birds. in D. M. Finch and T. E. Martin, editors. Ecology and Management of Neotropical Migrant Birds: a Synthesis and Review of the Critical Issues. . Oxford University Press, Oxford, U.K.

Press, W. H., S. A. Teukolsky, W. T. Vetterling, and B. P. Flannery. 1992. Numerical Recipes in C: the Art of Scientific Computing, 2nd Edition. . Cambridge University Press, Cambridge, U.K.

Robbins, C. S., D. Bystrak, and P. H. Geissler. 1986. The Breeding Bird Survey: Its First Fifteen Years, 1965-1979. Resource Publication 157. U.S. Fish and Wildlife Service, Washington D.C.

Robbins, C. S., J. R. Sauer, R. S. Greenberg, and S. Droege. 1989. Population declines in North American birds that migrate to the neotropics. Proceedings of the National Academy of Science, U.S.A. 86:7658-7662. 
Sauer, J. R., and S. Droege. 1990a. Recent population trends of the Eastern Bluebird. Wilson Bulletin 102:239-252.

Sauer, J. R., and S. Droege. 1990b. Wood Duck population trends from the North American Breeding Bird Survey. Pages 225-231 in L. H. Fredrickson, G. V. Burger, S. P. Havera, D. A. Graber, R. E. Kirby and T. S. Taylor, editors. Proceedings of the 1988 North American Wood Duck Symposium. ., St. Louis, Missouri.

Sauer, J. R., and S. Droege. 1992. Geographic patterns in population trends of neotropical migrants in North America. Pages 26-42 in J. M. Hagan and D. W. Johnston, editors. Ecology and Conservation of Neotropical Migrant Landbirds. . Smithsonian Institution Press, Washington D.C.

Sauer, J. R., B. G. Peterjohn, and W. A. Link. 1994. Observer differences in the North American Breeding Bird Survey. The Auk 111:50-62.

Searle, S. R., F. M. Speed, and G. A. Milliken. 1980. Population marginal means in the linear model: an alternative to least squares means. The American Statistician 34:216221.

Smith, C. R., D. M. Pence, and R. J. O'Connor. 1993. Status of Neotropical migratory birds in the northeast: a preliminary assessment. Pages 172-188 in D. M. Finch and P. W. Stangel, editors. Status and Management of Neotropical Migratory Birds; Proceedings of the 1992 Partners in Flight National Training Workshop; September 21-25; Estes Park, Colorado. General Technical Report RM-229. U.S.D.A. For. Serv. Rocky Mountain Forest and Range Experiment Station, Fort Collins, CO. 
Sokal, R. R., and J. F. Rohlf. 1981. Biometry. . W H Freeman and Co., New York, New York.

Taylor, S. M. 1965. The Common Bird Census - some statistical aspects. Bird Study 12:268-286.

Terborgh, J. 1989. Where Have All the Birds Gone?: Essays on the Biology and Conservation of Birds That Migrate to the American Tropics. . Princeton University Press, Princeton, New Jersey.

Terborgh, J. 1992. Why American songbirds are vanishing. Scientific American 1992(May):98-104.

Thomas, L. In Press. Monitoring long-term population change: why are there so many analysis methods? Ecology.

Thompson, F. R., III, S. J. Lewis, J. Green, and D. Ewert. 1993. Status of Neotropical migrant landbirds in the midwest: identifying species of management concern. Pages 145-158 in D. M. Finch and P. W. Stangel, editors. Status and Management of Neotropical Migratory Birds; Proceedings of the 1992 Partners in Flight National Training Workshop; September 21-25; Estes Park, Colorado. General Technical Report RM-229. U.S.D.A. For. Serv. Rocky Mountain Forest and Range Experiment Station, Fort Collins, Colorado.

Titus, K. 1990. Trends in counts of scissor-tailed flycatchers based on a nonparametric rank-trend analysis. Pages 164-166 in J. R. Sauer and S. Droege, editors. Survey Designs 
and Statistical Methods for the Estimation of Avian Population Trends. Biological Report 90(1). U.S. Fish and Wildlife Service, Washington D.C.

van Strien, A. J., R. Meiger, C. J. F. ter Braak, and T. J. Verstrael. in press. Analysis of monitoring data with many missing values: which method? in W. Hagemeijer and T. J. Verstrael, editors. Bird Numbers 1992. Distributions, Monitoring and Ecological Aspects. Proceedings of the 12th International Conference of IBCC and EOAC. . SOVON, Beek-Ubbergen, The Netherlands.

Wilcove, D. S., and J. Terborgh. 1984. Patterns of population decline in birds. American Birds 38:10-13.

Witham, J. W., and M. L. J. Hunter. 1992. Population trends of neotropical migrant landbirds in northern coastal New England. Pages 85-95 in J. M. Hagan and D. W. Johnston, editors. Ecology and Conservation of Neotropical Migrant Landbirds. . Smithsonian Institution Press, Washington D.C. 
TABLE 1. Summary of three Breeding Bird Survey trend estimation methods compared in this paper.

\begin{tabular}{|c|c|c|c|c|c|}
\hline \multirow[b]{2}{*}{ Component } & \multicolumn{3}{|c|}{ Methods } & \multicolumn{2}{|c|}{ Predicted effect of differences } \\
\hline & $\begin{array}{l}\text { USNBS }^{\mathrm{a}} \text { route } \\
\text { regression }^{\mathrm{b}}\end{array}$ & $\begin{array}{l}\text { CWS }^{a} \text { route } \\
\text { regression }\end{array}$ & $\begin{array}{l}\text { Nonparametric } \\
\text { rank trends }^{\mathrm{d}}\end{array}$ & Direction & Size \\
\hline $\begin{array}{l}\text { 1. Transformation } \\
\text { of counts }\end{array}$ & $\log ($ count +0.5$)$ & $\log ($ count +0.23$)$ & - & $\begin{array}{l}\text { Larger constant in USNBS decreases } \\
\text { absolute magnitude of trend and variance } \\
\text { relative to CWS }\end{array}$ & $\begin{array}{l}\text { Small, but greater at } \\
\text { low abundances }\end{array}$ \\
\hline $\begin{array}{l}\text { 2. Calculation of } \\
\text { route trend }\end{array}$ & $\begin{array}{l}\text { slope of linear } \\
\text { regression of log } \\
\text { count }\end{array}$ & $\begin{array}{l}\text { slope of linear } \\
\text { regression of log } \\
\text { count }\end{array}$ & rank trend & Unknown & Unknown \\
\hline 3. Covariables & observers & subroutes & none & $\begin{array}{l}\text { USNBS / CWS: unknown; } \\
\text { no covariables in rank trends may cause } \\
\text { positive bias due to increase in observer } \\
\text { quality }\end{array}$ & $\begin{array}{l}\text { USNBS / CWS: } \\
\text { likely small; } \\
\text { rank trends: likely } \\
\text { small-medium }\end{array}$ \\
\hline 4. Backtransform & $\begin{array}{l}\text { approx. exp (route } \\
\text { trend - variance/2) }\end{array}$ & performed later & - & $\begin{array}{l}\text { Back-transformation at this stage makes } \\
\text { USNBS trends more positive than CWS }\end{array}$ & Small \\
\hline 5. Regional trend & $\begin{array}{l}\text { weighted mean of } \\
\text { backtransformed } \\
\text { route trends within } \\
\text { physiographic strata }\end{array}$ & $\begin{array}{l}\text { weighted mean of } \\
\text { route trends on log } \\
\text { scale }\end{array}$ & $\begin{array}{l}\text { sum of route } \\
\text { trends }\end{array}$ & $\begin{array}{l}\text { Variance estimates likely higher for } \\
\text { CWS route regression than USNBS } \\
\text { method }\end{array}$ & Unknown \\
\hline
\end{tabular}




\section{TABLE 1. (CONTINUED)}

\begin{tabular}{|c|c|c|c|c|c|}
\hline $\begin{array}{l}\text { 6. Abundance } \\
\text { weight }\end{array}$ & $\begin{array}{l}\text { least squares mean / } \\
\text { geometric mean }\end{array}$ & $\begin{array}{l}\text { Winsorized least } \\
\text { squares mean }\end{array}$ & none & Unknown & May be large \\
\hline $\begin{array}{c}\text { 7. Precision } \\
\text { weight }\end{array}$ & $\begin{array}{l}\text { sum of squares of } \\
\text { years surveyed }\end{array}$ & $\begin{array}{l}\text { sum of squares of } \\
\text { years surveyed }\end{array}$ & none & Unknown & May be large \\
\hline 8. Area weight & $\begin{array}{l}\text { area of } \\
\text { physiographic } \\
\text { stratum within state }\end{array}$ & $\begin{array}{l}\text { proportion of } \\
\text { degree block } \\
\text { covered }\end{array}$ & none & Unknown & May be large \\
\hline 9. Backtransform & performed earlier & exp (regional trend) & - & $\begin{array}{l}\text { Simple exponentiation by CWS method } \\
\text { makes it more positive than USNBS }\end{array}$ & Small \\
\hline $\begin{array}{l}\text { 10. Variance } \\
\text { estimate }\end{array}$ & bootstrap & jackknife & $\begin{array}{l}\text { parametric } \\
\text { estimate }\end{array}$ & $\begin{array}{l}\text { USNBS / CWS: unknown; within-site } \\
\text { variance not accounted for in rank } \\
\text { trends, so variances smaller }\end{array}$ & $\begin{array}{l}\text { USNBS / CWS: } \\
\text { likely small; rank } \\
\text { trends unknown }\end{array}$ \\
\hline $\begin{array}{l}\text { 11. Significance } \\
\text { test }\end{array}$ & $z$-test & $t$-test & $z$-test & $\begin{array}{l}\text { USNBS / CWS: USNBS will give more } \\
\text { statistically significant results }\end{array}$ & $\begin{array}{l}\text { Small, but greater at } \\
\text { low abundances }\end{array}$ \\
\hline
\end{tabular}

a - USNBS = U.S. National Biological Service; CWS = Canadian Wildlife Service.

b - See Geissler (1984), Geissler \& Sauer (1990) and Peterjohn et al. (in press).

c - See Collins and Wendt (1989) and Erskine et al. (1992).

d - See Titus et al. (1990). 
TABLE 2. Pairwise comparisons among three Breeding Bird Survey trend estimation methods of the proportion of 115 species with trends in different directions (i.e., increasing in one method but decreasing in the other) or with different levels of statistical significance (i.e., $\mathrm{p}<=0.05$ in one method but $\mathrm{p}>0.05$ in the other).

\begin{tabular}{lccc}
\hline \hline & USNBS $^{\mathrm{a}}$ route regression vs. & USNBS $^{\mathrm{a}}$ route regression vs. & CWS $^{\mathrm{a}}$ route regression vs. \\
Trend & CWS $^{\mathrm{a}}$ route regression & nonparametric rank trends & nonparametric rank trends \\
\hline $\begin{array}{l}\text { Direction } \\
\text { Significance }\end{array}$ & $0.21(0.14,0.28)^{\mathrm{b}}$ & $0.25(0.18,0.32)^{\mathrm{b}}$ & $0.33(0.26,0.40)^{\mathrm{b}}$ \\
\hline
\end{tabular}

a - USNBS = U.S. National Biological Service; CWS = Canadian Wildlife Service.

b - Values given are proportions, with 95\% confidence limits (calculated using the normal approximation to the binomial distribution) in parentheses. If methods produced identical trends then the expected proportion of disagreement would be 0.0 . If there was no association between trends produced by the methods then the expected proportion would be approximately 0.5. 
TABLE 3. Estimates of the effect of sample size (number of routes) and species abundance (log mean count per survey) on the proportion of differences in the direction and statistical significance of species trends between three Breeding Bird Survey analysis methods. Estimates are from a logistic regression with $\mathrm{N}=115$ species.

\begin{tabular}{|c|c|c|c|c|}
\hline $\begin{array}{l}\text { Dependent } \\
\text { variable }\end{array}$ & $\begin{array}{l}\text { Independent } \\
\text { variable }\end{array}$ & $\begin{array}{l}\text { USNBS }^{\text {a }} \text { route regression vs. } \\
\text { CWS }{ }^{\text {a }} \text { route regression }\end{array}$ & $\begin{array}{c}\text { USNBS }^{\text {a }} \text { route regression vs. } \\
\text { nonparametric rank trends }\end{array}$ & $\begin{array}{l}\text { CWS }{ }^{\text {a }} \text { route regression vs. } \\
\text { nonparametric rank trends }\end{array}$ \\
\hline Direction & sample size & $0.14(-0.15,0.44)^{b}$ & $-0.05(-0.33,0.26)^{b}$ & $0.27(-0.06,0.56)^{b}$ \\
\hline of trend & log abundance & $0.25(-0.11,0.50)^{b}$ & $-0.19(-0.58,0.19)^{b}$ & $0.16(-0.27,0.48)^{b}$ \\
\hline Significance & sample size & $0.06(-0.21,0.35)^{b}$ & $0.16(-0.18,0.47)^{b}$ & $0.10(-0.24,0.43)^{b}$ \\
\hline of trend & log abundance & $0.10(-0.27,0.38)^{b}$ & $0.07(-0.36,0.43)^{b}$ & $-0.18(-0.56,0.25)^{b}$ \\
\hline
\end{tabular}

a - USNBS = U.S. National Biological Service; CWS = Canadian Wildlife Service.

b - Values given are the estimated change in proportion of difference between the highest value of the independent variable and the lowest value, with 95\% confidence limits in parentheses. If analysis methods produce more similar results with increasing values of the independent variable then the estimated change will be negative. In all cases the confidence limits span zero, indicating that we could not detect an effect of the independent variable. 


\section{FIGURE LEGENDS}

FIGURE 1. Number of species with increasing and decreasing trends from three analysis methods using the same Breeding Bird Survey data for 115 species from British Columbia. USNBS is U.S. National Biological Service and CWS is Canadian Wildlife Service.

FIGURE 2. Plot of the magnitude of trends estimated from U.S. National Biological Service (USNBS) route regression against the magnitude of trends from Canadian Wildlife Service (CWS) route regression for 115 species. If the methods produced identical trends then all the species would be on the dashed line. The solid line is the principal axis. 


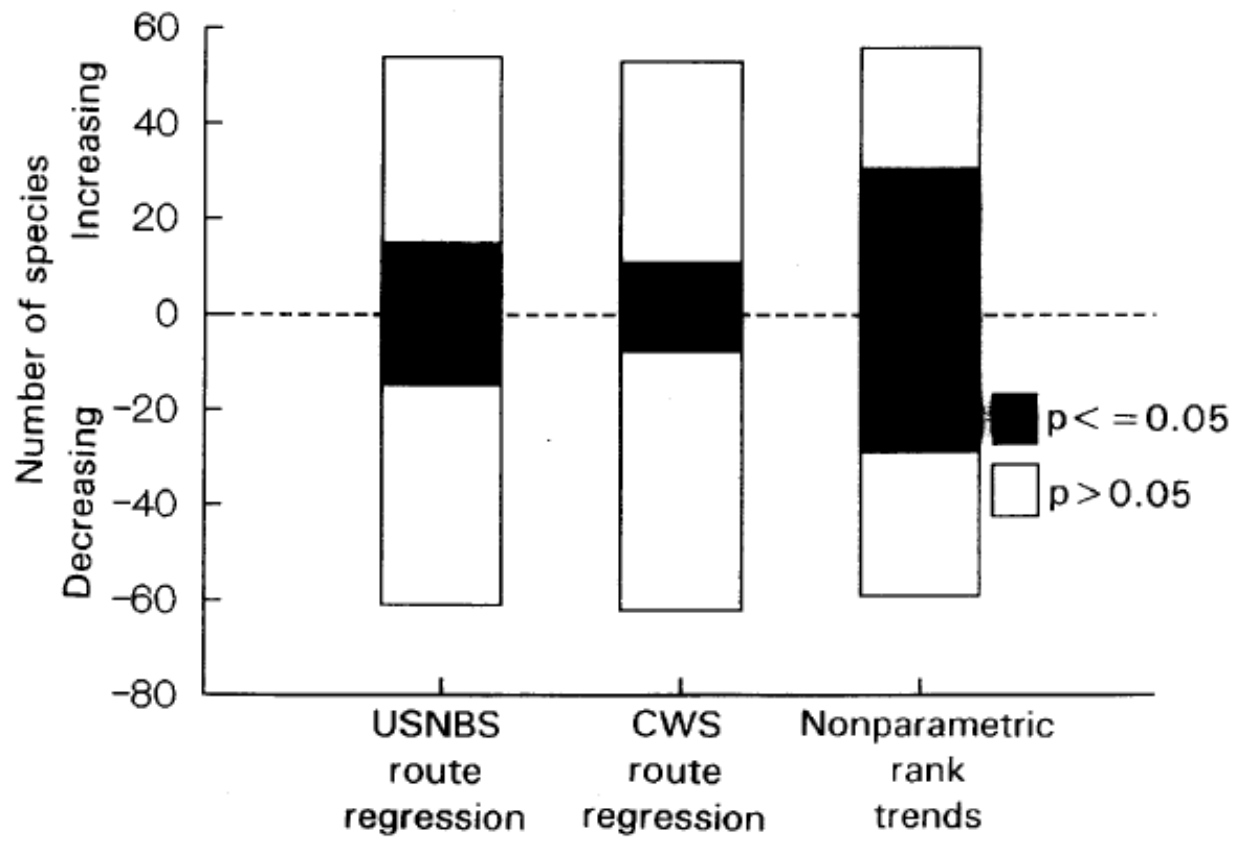

Figure 1. 


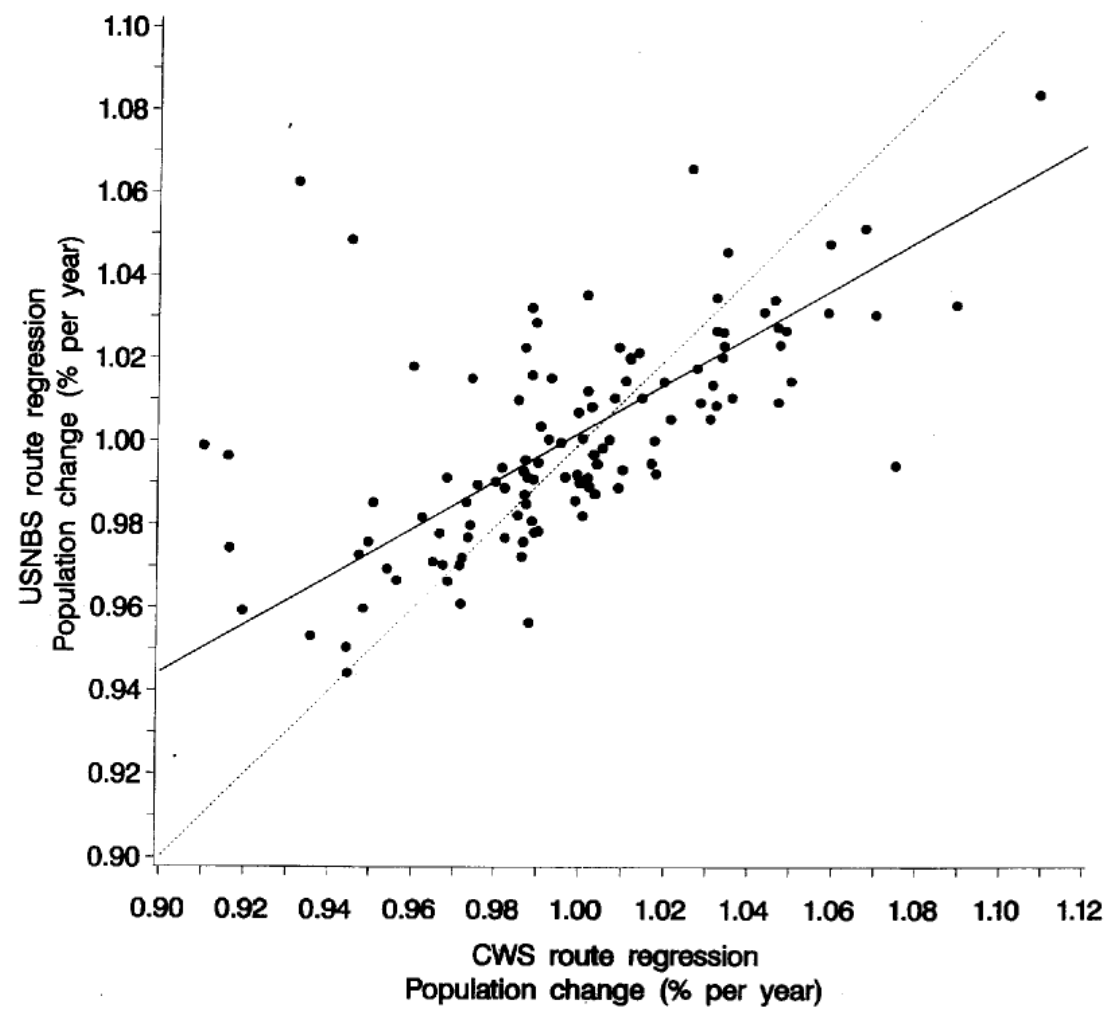

Figure 2. 